\title{
Transduction and Adaptation in Sensory Receptor Cells
}

\author{
V. Torre, ${ }^{1}$ J. F. Ashmore, ${ }^{2}$ T. D. Lamb, ${ }^{3}$ and A. Menini ${ }^{4}$ \\ 'Dipartimento di Fisica, Università di Genova, 16146 Genova, Italia, ${ }^{2}$ Department of Physiology, University of Bristol, \\ Bristol BS8 1TD, United Kingdom, ${ }^{3}$ Physiological Laboratory, University of Cambridge, Cambridge CB2 3EG, United \\ Kingdom, and Istituto di ${ }^{4}$ Cibernetica e Biofisica, C.N.R., 16149 Genova, Italia
}

\begin{abstract}
Sensory transduction shares common features in widely different sensory modalities. The purpose of this article is to examine the similarities and differences in the underlying mechanisms of transduction in the sensory receptor cells for vision, olfaction, and hearing. One of the major differences between the systems relates to the nature of the stimulus. In both the visual and olfactory systems a quantal mechanism of detection is possible, because the absorption of a photon or the binding of an odorant molecule provides an energy change significantly greater than the thermal noise in the receptor molecule. In hearing, on the other hand, the energy of a phonon is far lower, and detection occurs by a "classical" mechanism. For vertebrate photoreceptors and olfactory receptor cells, sensory transduction employs a $\mathbf{G}$ protein cascade that is remarkably similar in the two cases, and that is closely homologous to other $\mathbf{G}$ protein signaling cascades. For auditory and vestibular hair cells, transduction operates via a mechanism of direct coupling of the stimulus to ion channels, in a manner reminiscent of the direct gating of post-synaptic ion channels in various synaptic mechanisms. The three classes of sensory receptor cell share similarities in their mechanisms of adaptation, and it appears in each case that cytoplasmic calcium concentration plays a major role in adaptation.
\end{abstract}

[Key words: sensory transduction, sensory adaptation, photoreceptor, olfactory receptor cell, hair cell, vision, olfaction, hearing]

Many sensory systems can detect extremely faint signals. In vertebrates, the sensory hair cells of the inner ear can detect displacements of atomic dimensions in the tips of the stereocilia (Crawford and Fettiplace, 1985; Hudspeth and Markin, 1994); rod photoreceptors can detect individual photons (Hecht et al., 1942; Baylor et al., 1979; Baylor et al., 1984), and recently it has been shown that olfactory receptor cells may be able to detect individual molecules of odorant (Menini et al., 1995). These three different sensory modalities (hearing, vision, and olfaction) employ receptor cells with radically different cellular designs specialized for very different physical stimuli. But despite the great differences, it is possible to discern common motifs underlying mechanotransduction, phototransduction and olfactory transduction.

We acknowledge the support of the EC grant Esprit Basic Research Action SSS 6961 .

Correspondence should be addressed to V. Torre at the above address

Copyright $\mathcal{C} 1995$ Society for Neuroscience $0270-6474 / 95 / 157757-12 \$ 05.00 / 0$
The purpose of this article is to offer a unifying view of transduction in vertebrate sensory receptor cells, with emphasis on photoreceptors, olfactory receptor cells, and auditory receptors. We shall show that there are common engineering objectives, in the design of sensory receptors, which can be appreciated in the light of recent discoveries about the cellular basis of sensory transduction. We shall deal with the features of the physical stimuli that are detected, and then outline the two main classes of molecular mechanisms utilized: direct and indirect transduction. Finally, we consider the link between signal processing and sensory transduction and address amplification and extraction of signals as well as adaptation and the significance of noise.

\section{What Is Sensory Transduction?}

All animals have evolved sensory receptors, which provide the CNS with information about events in the physical world. These receptors consume metabolic energy and are designed so that a physical or chemical stimulus will trigger an electrical response in the cell membrane: a process known as sensory transduction.

\section{The sensory world: quantum versus classical}

It is helpful first to consider some basic properties of the physical stimuli encountered by the sensory receptors of vision, olfaction and hearing. In vision, the stimulus (light) is an electromagnetic wave in the frequency range $4-7.5 \times 10^{14} \mathrm{~Hz}$ (corresponding to wavelengths between 750 and $400 \mathrm{~nm}$ ). In olfaction, the stimulus (an odor) is a particular chemical substance carried in the air. In human hearing, the stimulus is a sound pressure wave in the frequency range $40 \mathrm{~Hz}$ to $20 \mathrm{kHz}$ (some mammalian species, such as echo-locating bats, detect frequencies above 100 $\mathrm{kHz}$ ).

The enormous difference in vibrational frequency between visual and acoustic stimuli implies a quantal mechanism for the detection of light, but a "classical" mechanism for the detection of sound (Block, 1992). A photon of wavelength $500 \mathrm{~nm}$ (with quantal energy $h v=4 \times 10^{-19} \mathrm{Joule} /$ photon or $57 \mathrm{kcal} / \mathrm{mol}$ ) has approximately 10 orders of magnitude more energy than an acoustic phonon, that is, the elementary energy of an acoustic wave, at a frequency of $10 \mathrm{kHz}$ (with quantal energy $h v=2 \times$ $10^{-19}$ Joule or $3 \times 10^{-6} \mathrm{cal} / \mathrm{mol}$ ). Detection of such stimuli is made against the thermal noise $k T$ associated with each degree of freedom of the transduction mechanism. At room temperature $\left(300^{\circ} \mathrm{K}\right), k T$ is approximately $4 \times 10^{-21}$ Joule/photon or 0.57 $\mathrm{kcal} / \mathrm{mol}$. This value is much smaller than the quantal energy in vision, but is much larger than the quantal energy in hearing. This implies that the basic limitation in hearing is set by thermal noise rather than by quantization of the stimulus. In the case of olfaction, the binding of a molecule of odorant to a receptor 

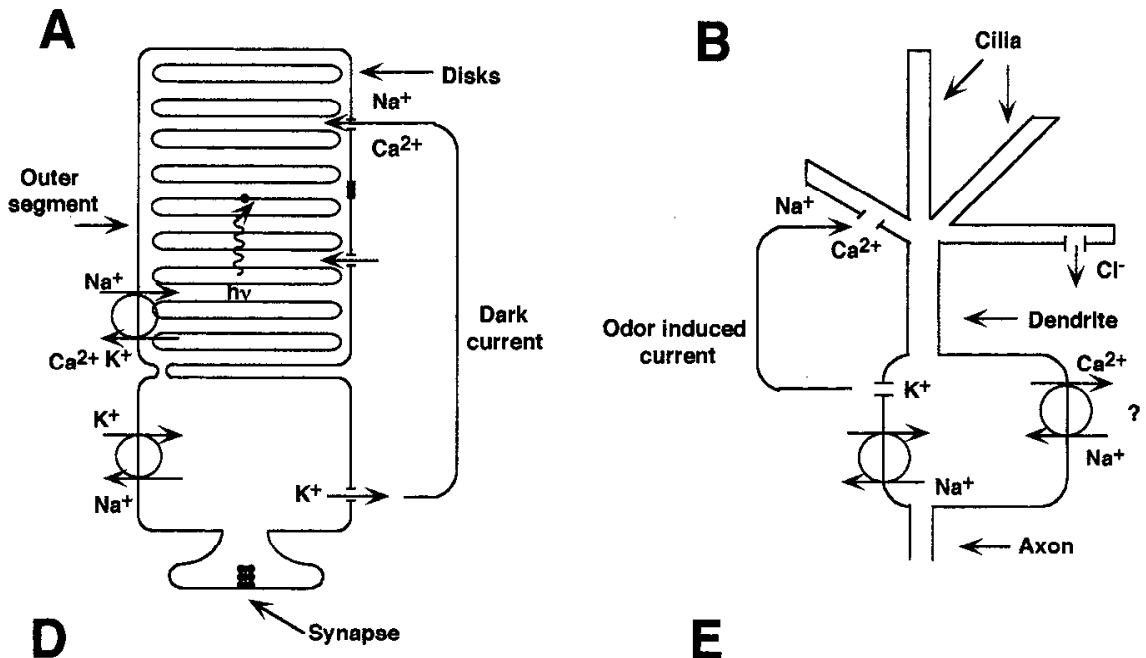

$\mathbf{E}$

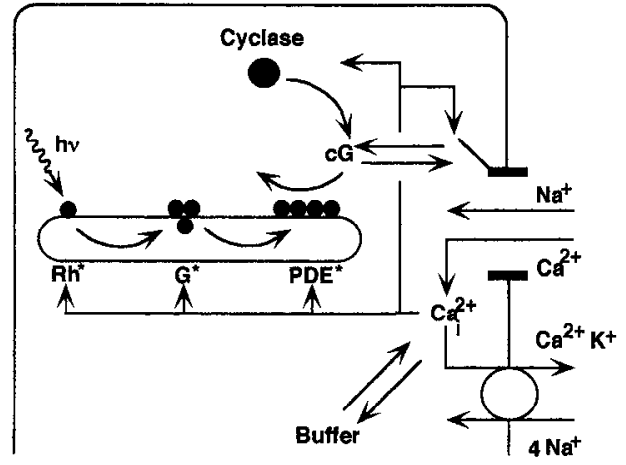

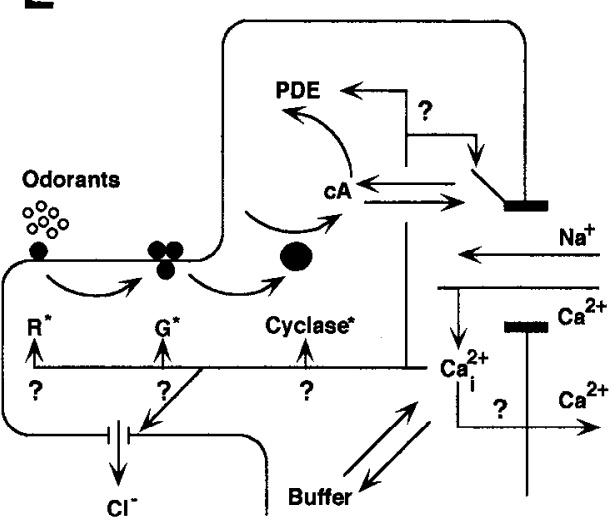

$\mathbf{F}$
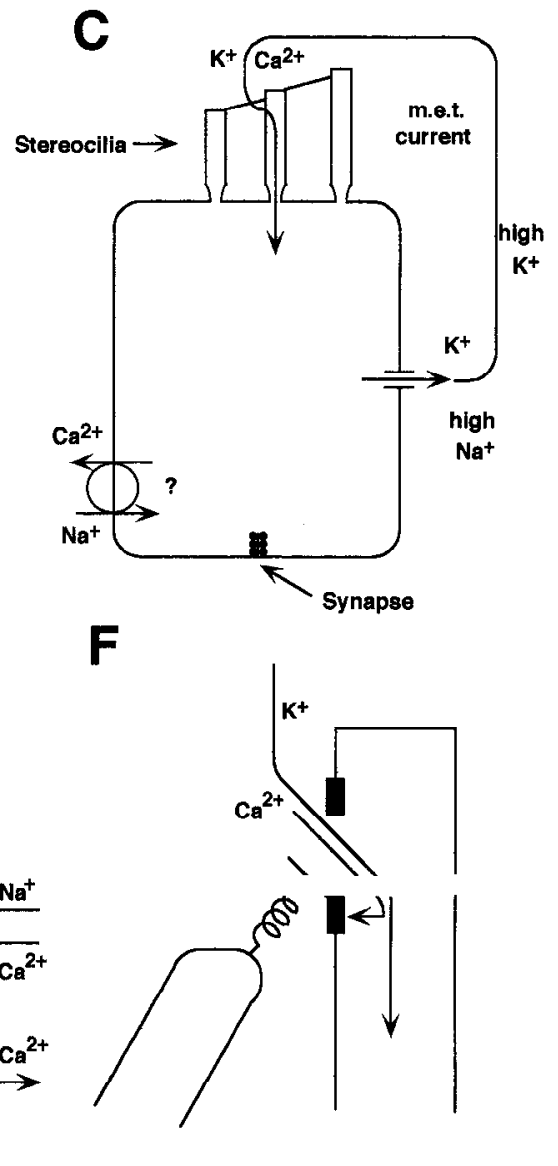

Figure 1. A-C, Schematics of a rod photoreceptor, an olfactory receptor cell and an auditory receptor cell. A, The rod photoreceptor is composed of an inner segment containing the normal cell organelles, and an outer segment composed of a stack of about a thousand membranous disks; the rhodopsin photopigment molecules are embedded in the disk membranes. In darkness, a loop of current circulates; current flows into the outer segment through cGMP-gated channels, and an equal current flows out from the inner segment. The cGMP-gated channels are permeable to cations and about $90 \%$ of the current flowing into the outer segment is carried by $\mathrm{Na}^{+}$, with the remaining $10 \%$ carried by $\mathrm{Ca}^{2+}$. The $\mathrm{Ca}^{2+}$ is extruded locally from the outer segment by a Na$/ \mathrm{Ca}^{2+}, \mathrm{K}^{+}$exchanger, while the $\mathrm{Na}^{+}$is extruded from the inner segment by a Na+$/ \mathrm{K}^{+}$pump. $B$, The olfactory receptor is composed of a cell body and an axon, together with 10-30 fine cilia emerging from a thicker dendrite. The membranes of the cilia contain the odorant receptor protein molecules. Odorants induce a current flowing into the cilia, which is carried by $\mathrm{Na}^{+}$and $\mathrm{Ca}^{2+}$. $\mathrm{Ca}^{2+}$ activates a chloride current in the cilia, and is extruded from the cell by unidentified mechanisms. $C$, The hair cell has about 100 stereocilia, which gate mechanosensitive channels directly, using a molecular spring ("tip link"). The stereocilia are bathed in a $\mathrm{K}^{+}$-rich medium, and the generator current is carried by $\mathrm{K}^{+}$and $\mathrm{Ca}^{2+} . D-F$, Schematics of transduction in a photoreceptor, an olfactory receptor cell and a hair cell. In $D$ and $E$, arrows indicate proposed regulatory roles of calcium on the different mechanisms. In photoreceptors, lowered calcium stimulates the activity of the cyclase, decreases the cGMP affinity for the channel and affects early stages of transduction. In olfactory neurons, calcium is known to regulate the channel affinity for cAMP and to activate a chloride current. In hair cells $\mathrm{Ca}^{2+}$ entering through the mechanosensitive channels can interact with the motile structure controlling the gating spring.

releases a binding energy $E$, which is related to the dissociation constant $K_{d}$ of binding by $E=-k T \ln K_{d}$ (Block, 1992). The dissociation constants for binding of odorants to receptor proteins are not known, but for reasonable values of $K_{d}$ between $10^{-8}$ and $10^{-3}, E$ is expected to range from 3.9 to $10.5 \mathrm{kcal} / \mathrm{mol}$.

\section{Interfacing stimulus and receptor cell}

Figure 1 shows receptor cells used in vision, olfaction, and hearing. In vision, an imaging system (the eye) delivers the visual stimulus to a large array of rod (which number about 100 million in the human eye) and cone (which number about 5 million) photoreceptors, with each receptor sampling a small region of the visual environment. The rods operate only at low light levels, and provide vision of very high sensitivity but at low spatial and temporal resolution (Fig. $1 A$ ). The cones provide vision at much higher resolution, and function over a million-fold range of intensities, from moonlight to sunlight conditions. About
100,000 cones are concentrated in the fovea, to provide very high spatial resolution. Humans possess cones of three spectral sensitivities, which underlie trichromatic color vision.

In olfaction, odorants sniffed in the vapor phase by air-breathing animals are brought via the olfactory mucus to olfactory receptor cells (Fig. $1 B$ ). Odorants are usually small molecules, with a molecular weight of less than $1000 \mathrm{Da}$. They excite the olfactory receptor cell by binding to specific receptor proteins in the cilial membrane. Recently, a large family of protein molecules with seven-transmembrane segments, closely homologous to the visual receptor protein rhodopsin, has been identified (Buck and Axel, 1991). This family appears to comprise at least several hundred different protein species which are presumed to represent olfactory receptor molecules specific for many different odorants.

In hearing, sound enters the ear canal, and is transmitted through the middle ear where it induces vibrations of the basilar 
membrane within the fluid-filled cochlea. These vibrations are detected by the mechanical displacement of stereocilia in the plasma membrane of the auditory receptors, the hair cells, attached to the basilar membrane (Fig. 1C). In lower vertebrates the vibration pattern does not depend on the sound frequency, and frequency sclcctivity arises from hair cell acting as a tuned filter. In mammals there is a division of hair cell function: inner hair cells are the actual transducers, while the outer hair cells act as mechanical motors. The pattern of basilar membrane vibration is actively controlled by the outer hair cells, and this ensures that each auditory frequency displaces only a localized population of inner hair cells. Mammalian inner hair cells are not individually turted; their frequency selectivity is determined by the concerted action of many outer hair cells.

The input stimulus for auditory receptors can therefore be considered either as the sound pressure wave which enters the ear, or alternatively as the mechanical displacement experienced by the hair cells. In practice, displacements of the hair cell bundle can only be measured reliably in isolated hair cells or in hair cell epithelia, but not in the intact animal.

\section{Some definitions: sensitivity, adaptation, and dynamic range}

The sensitivity, $S$, of transduction is defined as the incremental response per unit intensity of stimulus; that is, $S=d r / d I$, where $r$ is the response and $I$ is the stimulus intensity. In the case of the photoreceptor and the olfactory receptor, $S$ may be expressed in quantal terms (e.g., in pA/photopigment molecule isomerized, or pA per odorant molecule bound, respectively), provided that it is possible to estimate the number of quantal events induced by the test stimulus. In the auditory system, $S$ might be expressed as the response amplitude per unit of sound pressure level (in $\mathrm{mV} / \mathrm{Pa}$ ) in an intact preparation, or alternatively as the response per unit deflection of the tips of the stereocilia (in $\mathrm{mV}$ / $\mathrm{nm}$ ) in an isolated cell preparation.

The term dynamic range refers to the range of stimulus intensities over which a given sensory receptor is able to respond. It is convenient to define the dynamic range as the ratio of the stimulus intensities that elicit $95 \%$ and $5 \%$ of the maximal response; this is typically expressed in $\log _{10}$ units. Because of the existence of adaptation, though, it is important to indicate wheth er dynamic range is measured with a transient or a steady-state stimulus, since the steady-state dynamic range may be much greater than the transient dynamic range. The operating point refers to the stimulus which elicits a $50 \%$ response.

Ihe term adaptation refers to a decrease in receptor sensitivity that occurs in the presence of a maintained stimulus. The exact nature of the adaptational changes varies widely between different types of sensory receptors. Two extremes are represented by the hair cell and the photoreceptor. In turtle hair cells the application of a steady deflection of the hair bundle simply shifts the operating point of the transduction machinery, with little change in sensitivity (Crawford et al., 1989). In mammalian hair cells, on the other hand, relatively little adaptation of the transduction process takes place (Kros el al., 1992).

A very different situation occurs in photoreceptors, where the application of a bright steady light to a cone cell may result in a decrease in sensitivity (a desensitization) of more than 10,000 fold (Burkhardt, 1994). In photoreceptors, the desensitization follows Weber's Law, which specifies that sensitivity declines in inverse proportion to the background intensity:

$$
S_{\mathrm{sleady}}=S_{0} /\left(1+I_{\mathrm{stcady}} / I_{1 / 2}\right),
$$

where $S_{\text {steudy }}$ is the sensitivity in the presence of a steady stimulus of intensity $I_{\text {stealy }}$, and where $S_{0}$ is the sensitivity in the absence of steady stimulation and $I_{1 / 2}$ is the steady intensity that halfdesensitizes the response. A particular feature of desensitization in photoreceptors is the accelerated response kinetics caused by changes in the underlying biochemical nuachinery. Hence in the presence of a maintained stimulus, the receptor cell trades off reduced sensitivity for improved time response (i.e., increased bandwidth). Adaptation is also accompanied by a relaxation (or sag) in the cell's response to a prolonged stimulus.

\section{Molecular Mechanisms of Transduction}

The "special" senses comprise vision, hearing and vestibular sensation, and olfaction and taste. In these senses, the receptor cells are specialized neurons, which have evolved elaborate structures designed specifically for the transduction of physical stimuli into neural signals. In photoreceptors, transduction occurs in the outer segment (Fig. 1 $A$ ) and is initiated by the absorption of a photon by any one of the numerous rhodopsin molecules embedded in the stack of disk membranes. Olfactory transduction (Fig. 1B) takes place in the fine cilia which extend from the cell's dendritc; these cilia contain a diversity of receptor molecules that bind odorants. In hair cells of the auditory and vestibular systems (Fig. 1C), transduction occurs in the hundle of stereocilia at the apical pole.

All sensory receptor cells share the feature that a stimulus causes modulation of the flow of a receptor current that circulates in a local loop (Fig. 1). Modulation of the current is achieved by the galing of ion channels located in the plasma membrane of the specialized sensory region of the cell. In olfactory receptor cells, the altered receptor current triggers action potentials that are conducted along the cell's axon. In vertebrate photoreceptors and in hair cells, the altered current gives rise to a graded change in membrane potential, which is transmitted across a synapse only a short distance from the transducing region.

The molecular mechanisms of transduction found in different sensory receptors can be divided into two distinct classes: direct and indirect activation. In photoreceptors and many chemoreceptors, the sensory stimulus modulates the flow of receptor current by an indirect (or second messenger) pathway. This pathway typically involves a $G$ protein cascade of reactions, and leads to modulation of the cytoplasmic concentration of a chemical messenger (for example, a cyclic nucleotide) and in turn to the modulation of ion channel gating. With directly activated transduction, exemplified by mechanoreceptors, the stimulus leads directly to the gating of ion channels, without the intervention of a second messenger.

\section{Indirect activation}

$G$ Protein cascades. G Protein cascades are characterized by the presence in the transducing membrane of three species of protein molecule: a receptor protein $(\mathrm{R})$, a $\mathrm{G}$ protein $(\mathrm{G})$, and an effector protein (E); (Lefkowitz et al., 1986; Ross, 1989; Stryer, 1991) (Fig. 1D,E). Activation of the cascade by a stimulus proceeds according to: Stimulus $\rightarrow \mathrm{R}^{*} \rightarrow \mathrm{G}^{*} \rightarrow \mathrm{E}^{*}$, where the asterisks indicate activated forms. The occurrence of these reactions depends crucially on intermolecular collisions resulting from lateral diffusion of the protein molecules within the membrane (Lamb and Pugh, 1992). A single molecule of $R^{*}$ can repeatedly (or catalytically) activate molecules of $G$ protein to $G^{*}$ (by triggering the exchange of a GTP for a GDP on G). Each activated 
$\mathrm{G}^{*}$ continues diffusing until it contacts a molecule of $\mathrm{E}$, whereupon the two proteins bind to form $G^{*}-E$, which represents the activated effector, $\mathrm{F}^{*}$.

An important feature of $\mathrm{G}$ protein transduction is its potential to provide very high amplification, through the cascading of two stages of gain. The first stage is provided by the activated receptor protein $\mathrm{R}^{*}$, which catalytically activates the $\mathrm{G}$ protein. A second stage of gain is provided by the activated effector protein $E^{*}$, which is typically an enzyme that catalyzes the synthesis (or destruction) of a cytoplasmic messenger molecule.

$\mathrm{G}$ Protein cascades form a closely homologous set of cellular signaling mechanisms, utilized not only in sensory receptors but also in many hormonal and synaptic systems, where the mechanism was first elucidated (Lefkowitz et al., 1986). The corresponding proteins bear a remarkable similarity to each other, even in systems as apparently diverse as the photoreceptor and the $\beta$-adrencrgic mechanism. The receptor proteins (R) are members of a family, sharing homologous amino acid sequences and a common molecular structure comprising seven-transmembrane segments (Lefkowitz et al., 1986; Ross, 1989; Buck and Axel, 1991; Stryer, 1991; Reed, 1992). The G proteins, too, are closely related, each comprising a hetero-trimer in which the $\alpha$-subunit binds GTP to bring about activation. One of the main differences between cascades in various cell types relates to the effector protein, E. In the olfactory receptor cell (as well as in the $\beta$-adrenergic system), $E$ is adenylyl cyclase, the enzyme that synthesizes cAMP (Fig. $1 E$ ). In the photoreceptor, $E$ is the phosphodiesterase (PDE) that hydrolyzes cGMP (Fig. 1D).

Gating of ion channels. Modulation of the cyclic nucleotide concentration within photoreceptors and olfactory receptor cells modulates the opening of cyclic nucleotide-gated ion channels. The physiological and molecular properties of these channels are broadly similar in photoreceptors and olfactory receptor cells (Yau and Baylor, 1989; Torre and Menini, 1994; Zufall et al., 1994; Menini, 1995). The genes encoding the cyclic nucleotidegated channels have been cloned, and their amino acid sequences are highly homologous (Kaupp, 1991).

In photoreceptors, the average density of these channels in the outer segment cell membrane is of the order of $600 / \mu \mathrm{m}^{2}$ (Karpen et al., 1992), so that each rod contains at least 100,000 channcls. In olfactory receptor cells, the density of cAMP-gated channels in the ciliary membrane is about $2500 / \mu \mathrm{m}^{2}$ (Kurahashi and $\mathrm{Ka}$ neko, 1991). The photoreceptor channels have the property that they flicker rapidly between open and closed states (Torre et al., 1992; Sesti et al., 1994). Their mean open time is less than 40 $\mu$ sec, and their single channel conductance in the absence of divalent cations has been estimated as 25 pS (Yau and Baylor, 1989; Taylor and Baylor, 1995) or as greater than $60 \mathrm{pS}$ (Torre et al., 1992; Sesti et al., 1994). However, physiological concentrations of extracellular $\mathrm{Ca}^{2+}$ or $\mathrm{Mg}^{2+}$ have a very powerful blocking effect, so that under normal conditions the single channel conductance is effectively reduced to a much smaller value. The opening of each ionic channel requires the binding of at least three molecules of cyclic nucleotide. In salamanders, halfmaximal activation of the channels occurs at a cGMP concentration of about $10 \mu \mathrm{M}$ in rod photoreceptors, and at a cAMP concentration of about $20 \mu \mathrm{M}$ in olfactory receptor cells.

These channels are permeable to divalent cations but only weakly selective for the passage of different monovalent cations. The entry of calcium through the channels plays a critical role in adaptation in photoreceptors, and appears likely also to do so in olfactory receptor cells.
Because of the high amplification of the enzymatic cascades in phototransduction and chemotransduction, and the high density of cyclic nucleotide-gated channels in the membrane, transduction in these sensory neurons involves the synthesis or removal of many thousands of molecules of cyclic nucleotide and the opening or closure of many thousands of ion channels.

\section{Direct activation}

"Direct activation" refers to those systems, exemplified by hair cells, where the transduction channel is gated by the stimulus, without the intervention of a second messenger. Direct activation allows fast gating of the channel and is suited for high frequency auditory stimuli. It is believed that the activation energy is supplied by a deformation of the channel, but the precise mechanism of coupling of the sensory stimulus (e.g., hair cell displacement) to gating of the channel is unknown. There is evidence that the coupling arises from linkages between the channel and the cytoskeleton (as in the case of stretch activated channels in muscle spindle fibers), or from a specialized extracellular protein (as in the case of the hair cell; Fig. $1 C$ ). However, in the one case where an identified mechanosensory protein has been sequenced and expressed (a major conductance channel in a bacterial membrane) the stimulus may be coupled to the channel through in-plane forces in the membrane itself (I Iamill and McBride, 1994). As yet there is no sequence information for a positively identified vertehrate mechanosensory channel.

Most mechanosensory channels are cation-selective. Stretchactivated channels have been studied using patch-clamp electrodes for which single-channel conductances of between 16$100 \mathrm{pS}$ have been recorded. In hair cells the conductance of a single transducing channel appears to be about $100 \mathrm{pS}$.

\section{The Photoreceptor}

\section{The $G$ protein cascade in the photoreceptor}

The rod photoreceptor employs an archetypal version of G protein signaling (McNaughton, 1991; Stryer, 1991; Pugh and Lamb, 1993). A photon activates the receptor protein rhodopsin $\mathrm{R}$ to $\mathrm{R}^{*}$, by isomerizing the attached retinal chromophore from its bent 11 -cis form to the straight all-trans form; $\mathrm{R}^{*}$ then activates the cascade in the manner described above. $\Lambda$ single $R^{*}$ causes activation of the $G$ protein at a rate of about $1000-5000$ $\mathrm{G}^{*} / \mathrm{sec}$ at room temperature (Stryer, 1991; Lamb and Pugh, 1992). The activated effector protein, $E^{*}$ (the cyclic nucleotide phosphodiesterase, PDE*), hydrolyzes cGMP at a rate of 1000 4000 molecules/sec. Therefore light triggers a decrease in cGMP concentration, leading to the closure of cGMP-gated channels in the plasma membrane and hence to a reduction in the cell's circulating current (Fig. 2A). Recently, the molecular steps in the $G$ protein cascade of phototransduction have heen analyzed quantitatively and a simple expression for the predicted time course of the rising phase of the light response has been derived (Lamb and Pugh, 1992; Pugh and Lamb, 1993).

Despite the much lower sensitivity and faster response kinetics of cone photoreceptors, their transduction mechanism is virtually identical to that of rods. The corresponding proteins are very similar to each other, and they display closely equivalent kinetic parameters (Hestrin and Korenbrot, 1990; Pugh and Lamb, 1993). In some respects the cone is comparable to a lightadapted rod, exhibiting a desensitized and accelerated response. There are some major differences, though: in particular, the cone is much noisier than the rod (see below), and its response does not saturate at high intensities of steady illumination, in the way 

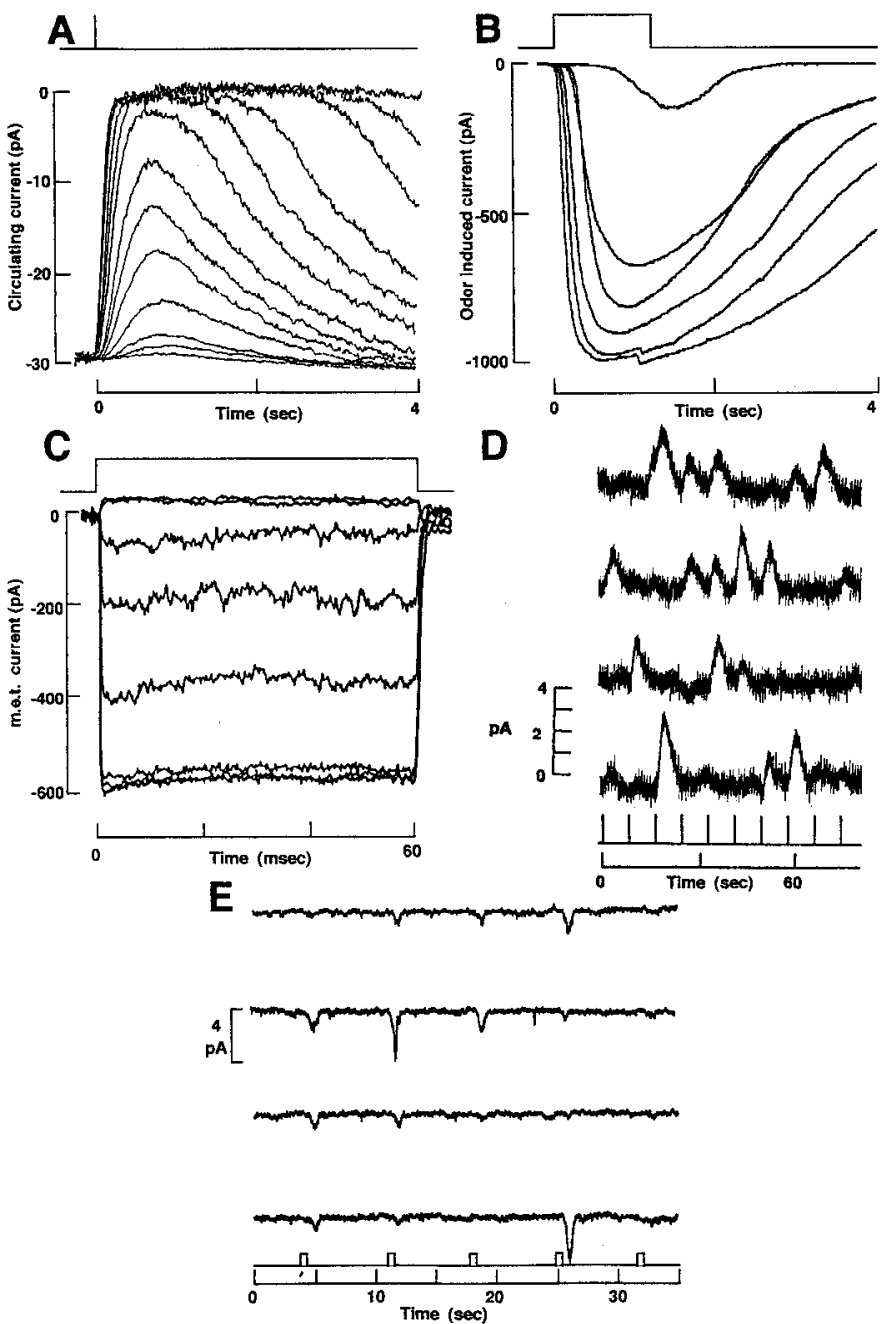

Figure 2. $A-C$, Families of response currents evoked by brief stimuli of increasing intensity in a photoreceptor, an olfactory receptor cell, and a hair cell. A, Suction pipette recordings obtained from a newt rod following brief flashes of light of increasing intensity of a duration of $50 \mathrm{msec}$ at the wavelength of $498 \mathrm{~nm}$ (redrawn from Forti et al., 1989). The light intensity of the dimmest flash was equivalent to 3 photoisomerization ( $\mathrm{Rh}^{*}$ ) per flash and the brightest to $24,000 \mathrm{Rh}^{*}$ per flash. $B$, Recordings from a salamander olfactory receptor cell, obtained by whole cell voltage clamping, in response to the application for $1.2 \mathrm{sec}$ of the odorant cineole at concentrations ranging from $1 \mu \mathrm{M}$ to $100 \mu \mathrm{M}$ (redrawn from Firestein et al., 1993). C, Recordings from hair cells in a mouse organolypic cochlear culture during 60 misec displacentents of the stereocilia (redrawn from Rüsch et al., 1994). $D$ and $E$, Responses to repeated stimuli illustrating the quantal nature of the response. $D$, Responses of a toad rod to consecutive very dim flashes of light (redrawn from Baylor et al., 1979). $E$, Responses of a salamander olfactory receptor cell to consecutive brief exposures to cineole (redrawn from Menini et al., 1995).

that the rod's response does (Baylor and Hodgkin, 1974; Burkhardt, 1994). The molecular basis for these differences in response properties between rods and cones is not yet fully understood.

\section{Response families}

A typical family of rod photoresponses is illustrated in Figure $2 A$. These recordings were obtained from a newt rod, using the suction pipette technique, in response to a series of flashes of increasing intensity. Prior to the flashes, a steady "dark current" of $30 \mathrm{pA}$ circulated, with current flowing into the outer segment and out of the inner scgment (Fig. $1 A$ ). In response to illumination, this circulating current was reduced in a graded manner: dim flashes elicited small reductions in circulating current, while bright flashes caused its complete and rapid elimination.

The relationship between response amplitude $r$ and light intensity $I$ (Fig. $3 D$ ) is most simply described by an exponential saturating function (Baylor et al., 1974; Lamb et al., 1981):

$$
r / r_{\max }=1-\exp (-k l)
$$

where $k$ is a constant at any fixed time. This relation shows that for brief flashes the dynamic range of the photoreceptor (as defined above) is $1.8 \log _{10}$ units, or a 60 -fold range of intensities.

Comparison of results from a variety of species (ranging from mammals to lower vertebrates) shows that the underlying parameters of the transduction cascade appear to be closely similar across species. Interspecies differences in response kinetics and amplification can be accounted for largely on the basis of differences in outer segment dimensions and differences in body temperature (Pugh and Lamb, 1993).

\section{Ultimate sensitivity: response to a single photon}

The dark-adapted rod photoreceptor achieves the ultimate in sensitivity, responding reliably to the absorption of individual photons. Figure $2 D$ illustrates the response of a toad rod to presentation of a series of very dim flashes of nominally identical intensity. Because the mean number of photons absorbed per flash is very small (about 0.5), quantal effects are significant (see "What is sensory transduction" above) and a histogram of the distribution of response amplitudes shows clear evidence for quantization (not illustrated; see Baylor et al., 1979b). The response to absorption of a single photon has an amplitude of just over $1 \mathrm{pA}$ (about $5 \%$ of the dark current) and a time-to-peak of about $1 \mathrm{sec}$, in a toad rod at room temperature. This indicates that the absorption of a single photon by any one of the 2 billion rhodopsin molecules in the rod causes the closure of one twentieth of all the channels present in its outer segment-a spectacular feat of amplification. The quantal response has a smooth time-course, indicating that it involves the activity of a large number of channels. Furthermore, the amplitude and shape of the quantal responses is reproducible, varying by less than $25 \%$ of the mean.

\section{Noise}

The light-evoked signals in photoreceptors must be detected in the presence of any noise in the cell, and this noise can be very large. Although there is intrinsically a large amount of "channel noise" in these cells, the great majority of this high frequency noise is filtered out by the cell's electrical time constant. Hence, the physiologically significant noise arises predominantly from the "slow" processes associated with the transduction process.

In rods, one such source of noise is the spontaneous occurrence of photon-like events even in complete darkness. Baylor et al. (1980) presented evidence that these events arise from thermal isomerization of rhodopsin molecules, that is, through the occasional isomerization of $\mathrm{R}$ to $\mathrm{R} *$ by thermal energy. Despite the occurrence of these isomerizations, each rhodopsin molecule is extremely stable, with a mean thermal life-time of about 3000 years (based on a $50 \mathrm{sec}$ mean interval between dark isomerizations and a total of 2 billion rhodopsins/rod). These quantal events in darkness appear to be highly significant for the overall visual system, and they probably set the limit to our visual performance at low light levels. A second source of noise 

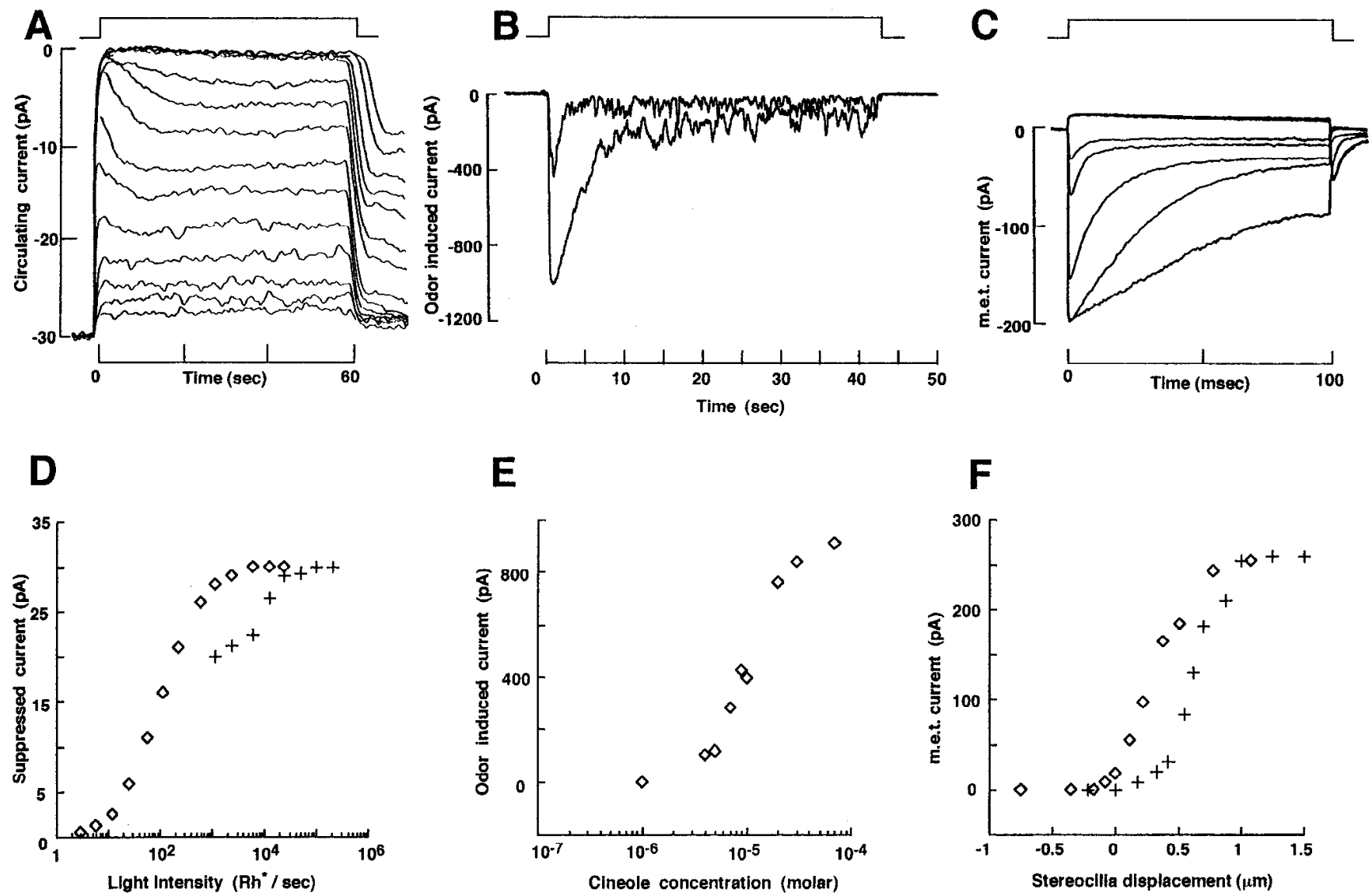

Figure 3. A-C, Families of responses to long stimuli of increasing intensity in a photoreceptor, an olfactory receptor cell and a hair cell. The duration of the stimulus is indicated by a trace above each graph. $A$, Suction pipette current recordings from a newt rod, in response to 60 sec steps of light of increasing intensity (redrawn from Forti et al., 1989). The dimmest light was equivalent to $5 \mathrm{Rh}^{*} / \mathrm{sec}$ and the brightest to 220,000 $\mathrm{Rh}^{*} / \mathrm{sec}$. $B$, Whole-cell current recordings from a salamander olfactory receptor cell in response to a steady 40 sec exposure to $10 \mu \mathrm{M}$ (upper trace) and $70 \mu \mathrm{M}$ (lower trace) of the odorant cineole (redrawn from Menini et al., 1995). $C$, Averaged mechanoelectrical transducer currents measured in an isolated turtlc hair cell under whole-cell voltage clamp in response to a steady 100 msec displacement of the stereocilia (redrawn from Crawford et al., 1989). $D-F$, Response amplitude versus stimulus intensity, in the absence $(\diamond)$ or in the presence of an adapting background ( + ) for a photoreceptor, an olfactory receptor cell and a hair cell, respectively. Data in $D$ redrawn from Forti et al. (1989), in $E$ from Menini et al. (1995), and in $F$ from Crawford et al. (1989).

is the so-called "continuous" component, which is likely to be caused by fluctuations in the enzymatic cascade of transduction (Baylor et al., 1980). A third noise source is apparent during the period of "dark adaptation" following exposure of the rod to an intense light which isomerizes (or "bleaches") more than about $0.1 \%$ of the photopigment. These fluctuations do not represent thermal isomerization of the pigment, but instead appear to arise from activation of the cascade by the photoproducts of $\mathrm{R}^{*}$ (Lamb, 1980, 1981; Leibrock et al., 1994).

In cones, the dark noise is much larger than in rods, with a peak-to-peak amplitude of about $20 \%$ of the maximal voltage response (Lamb and Simon, 1976); this value applies in the case of cones which are not electrically coupled to their neighbors. On the other hand, the single-photon response in cones is much smaller and faster than that in rods, and corresponds to suppression of only about $0.1 \%$ of the circulating current. From these figures it can be calculated that the noise in turtle cones is equivalent to a steady light intensity of about 2000 photoisomerizations/sec (Lamb and Simon, 1977). This intensity of equivalent background in a turtle cone is about 100,000 times greater than the equivalent background in a toad rod resulting from thermal activation of rhodopsin.

\section{Light adaptation and dynamic range}

When a steady light is presented to a rod, a significant fraction of the circulating current is initially suppressed, but after some seconds the circulating current partly recovers, as a consequence of light adaptation (Fig. 3A). The mechanism underlying light adaptation involves a light-induced drop in intracellular calcium concentration (Torre et al., 1986; Matthews et al., 1988; Nakatani and Yau, 1988; Matthews, 1991; Kaupp and Koch, 1992). In darkness calcium enters the cell via the cGMP-gated channels, and is extruded via sodium-calcium exchange; the lightinduced closure of channels then reduces the calcium influx, and causes a reduction in cytoplasmic calcium concentration (Yau and Nakatani, 1985; Ratto et al., 1988; Lagnado et al., 1992; Gray-Keller and Detwiler, 1994; McCarthy et al., 1994).

Intracellular calcium affects several important steps in phototransduction (Fig. 1D). A decrease in intracellular calcium concentration stimulates the guanylate cyclase (Koch and Stryer, 1988; Koch, 1991) through the mediation of a $23 \mathrm{kDa}$ protein designated GCAP (guanylyl cyclase activating protein, Gorczyca et al, 1994). Changes in calcium concentration also affect the gain of one or more stages of the enzymatic cascade (Torre et 
al., 1986), and this has been shown to occur at least in part through the action of a separate $23 \mathrm{kDa}$ protein called recoverin or S-modulin, which controls the rate of rhodopsin phosphorylation (Kawamura and Murakami, 1991; Stryer, 1991; Kawamura, 1993a,b). Furthermore, lowered calcium concentration has also been reported to mediate a separate effect on rhodopsin gain (Lagnado and Baylor, 1994), and to increase the channel affinity for CGMP (Hsu and Molday, 1993). These multiple pathways, in which calcium regulates several different biochemical steps, provide a complex negative-feedback control system. The overall effect of this intricate system is to provide an automatic gain control for transduction, which gives rise to photoreceptor light adaptation.

Light adaptation results in desensitization of the photoreceptor in accordance with Weber's law, as described in Equation 1 (Baylor and Hodgkin, 1974). Such adaptation has been shown to occur in a wide variety of rod and cone photoreceptors, from lower vertebrates to mammals (Fain and Matthews, 1990). This automatic gain control extends the rod's steady state dynamic range at least a 10 -fold beyond that measured at the peak (Fig. $3 D$ ). In cones, the effects of light adaptation are manifested over a much wider range of intensities, and the dynamic range may be extended by many orders of magnitude (Burkhardt, 1994).

\section{The Olfactory Receptor}

The enzymatic cascade in olfactory receptor cells

Olfactory transduction is initiated by the binding of odorant molecules to receptor proteins in olfactory receptor cells. These proteins belong to the superfamily of receptors coupled to G-proteins (Buck and Axel, 1991). As described above in "G Protein cascades," the activated receptor protein $\mathrm{R} *$ triggers a G-protein cascade and ultimately causes the activation of the effector protein adenylyl cyclase that synthesizes cAMP (Lamb and Pugh, 1992; Reed, 1992). The increased cAMP concentration leads to the opening of ion channels in the ciliary membrane, resulting in an odorant-induced current carried by $\mathrm{Na}^{+}$and $\mathrm{Ca}^{2+}$ (Nakamura and Gold, 1987; Kurahashi, 1989). Recently, it has been shown that the odorant-induced current is composed not only of the cationic component through the cAMP-gated channels, but also by an inward anionic component carried by $\mathrm{Cl}^{-}$(Kleene and Gesteland, 1991; Kurahashi and Yau, 1993), presumably activated by the $\mathrm{Ca}^{2+}$ influx through the cAMP-gated channels. The role of the $\mathrm{Ca}^{2+}$-activated chloride current in olfactory transduction has not yet been established.

Many basic properties of olfactory receptor cells still need to be clarified. A large number of receptor proteins exist (Buck and Axel, 1991), but little is known about their odor specificity. For example, it is not known whether a single cell expresses only one type of receptor protein (Ressler et al., 1994; Shepherd, 1994), or even what the membrane density of receptors might be.

\section{Response families}

A family of current responses, obtained by briefly exposing an olfactory receptor cell to a series of exposures of increasing odorant concentration, is shown in Figure $2 B$ (Firestein et al., 1993). The odor-induced current has a slow time course and greater concentrations of odorant induce progressively larger currents (Firestein and Werblin, 1989). By comparing the response families of Figure 2, $A$ and $B$, it is evident that the odorant-induced current has a timc-course broadly resembling that of the light-suppressed current in photoreceptors. This may not be surprising, since the transduction mechanism in olfactory receptor cells and photoreceptors involves a similar enzymatic cascade. The relation between odorant concentration and the amplitude of the induced current at the peak of the response has been described by the equation

$$
r / r_{\max }=c^{n} /\left(c^{n}+C_{1 / 2}{ }^{n}\right)
$$

where $c$ is the odorant concentration, $C_{1 / 2}$ the odorant concentration evoking half of the maximal response and $n$ the Hill coefficient, which indicates the degree of cooperativity in the response-concentration relation (Firestein et al., 1993). The experimental data were always well-fitted by sigmoidal curves ( $n$ $>1$ ), indicating that the amplitude of the response rises more steeply than linearly as a function of odorant concentration, and that therefore the relation between stimulus intensity and response is steeper than in photoreceptors. Accordingly, the dynamic range of olfactory receptor cells is smaller than that of photoreceptors: about $1.2 \log$ units at the response peak (Fig. $3 E$ ), compared with $1.8 \mathrm{log}$ units for a rod (Fig. $3 D$ ). Different olfactory receptor cells respond to the same odorant with different sensitivity. In salamander the value of $K_{1 / 2}$ for cineole varies between approximately $1 \mu \mathrm{M}$ and $100 \mu \mathrm{M}$ (Firestein et al., 1993).

\section{Adaptation}

When an olfactory receptor cell is exposed to high odorant concentrations for an extended period, the induced current exhibits an initial transient rise, but within a few seconds decreases to a much lower plateau level (Firestein et al., 1990; Kurahashi and Shibuya, 1990). The plateau is also characterized by pronounced fluctuations (Fig. 3B). Both the plateau response and its fluctuations disappear upon removal of the odorant (Menini et al., 1995).

This partial recovery of response level in olfactory receptor cells appears qualitatively similar to the recovery of the circulating current in photoreceptors during steady illumination. However, it is not yet known whether olfactory receptor cells share the other features of adaptation in photoreceptors; that is, whether a change in sensitivity and dynamic range occurs in the presence of a steady odorant concentration. The tendency for the response to recover during prolonged stimulation has been shown to be reduced when extracellular calcium is lowered $(\mathrm{Ku}-$ rahashi and Shibuya, 1990). Although this is suggestive of a role for calcium in adaptation of olfactory receptor cells, the underlying mechanisms have not been established.

\section{Ultimate sensitivity and current fluctuations}

Figure $2 E$ illustrates current responses elicited by a series of identical brief exposures to a low concentration of odorant. These responses exhibit considerable variability in their amplitude: in some of the trials there was no apparent response, in others a small response of about $0.4 \mathrm{pA}$, and occasionally larger responses of 2-4 pA, and even one response of $9.5 \mathrm{pA}$. Analysis of the amplitude distribution of these events suggests the existence of a quantal response in the range $0.3-1 \mathrm{pA}$. It seems likely that such a quantal event would be caused by the binding of a single molecule of odorant to a receptor protein (Menini et al., 1995).

\section{The Auditory and Vestibular Receptor}

Structures in and around hair cells

The structures of the inner ear are specialised to detect acoustic frequency modulations in air pressure (in the cochlea), angular 
acceleration of the head (in the semicircular canals) or the gravity vector (as in the sacculus and utriculus). Their common sensory element is the hair cell, a polarised neuro-epithelial cell, which bears at its apical surface a bundle of about 100 rod-like stereocilia, which can be deflected by a mechanical stimulus. The geometry of the structures surrounding the hair cells ensures that the external physical stimulus is delivered to their cell as a displacement stimulus. Incoming sound initiates a travelling wave in the basilar membrane of the mammalian cochlea, whose amplitude peaks at a position dependent upon the sound frequency. The stereocilia of hair cells located at the site of peak excursion of the basilar membrane are then deflected as a result of the geometry of the organ of Corti, the hair cell bearing epithelium that rides on the basilar membrane.

The apparatus of the mammalian cochlea thus transforms the input acoustic wave before its detection by the hair cells. As described below, this transformation includes both low-noise amplification and spectral decomposition of the incoming sound. To accomplish this, the mammalian cochlea relies on the concerted action of many hair cells (Dallos, 1992; Ashmore, 1994). The organ of Corti within the cochlea contains two classes of hair cell: inner hair cells, which act as sensory cells for the auditory nerve, and outer hair cells which are now considered to be motor cells involved in a local positive-feedback loop to provide enhancement of the travelling wave in the basilar membrane.

\section{Amplification}

At auditory threshold, the peak displacement of the basilar membrane is about $0.3 \mathrm{~nm}$ (Sellick et al., 1982). This movement includes the amplification provided by the outer hair cells. Without the operation of the cochlear amplifier, the peak displacement would be about 100 -fold less, (i.e., approximately 0.003 $\mathrm{nm})$.

The nature of the cochlear amplification refiects the properties of the outer hair cell (Ashmore and Kolston, 1994). As well as being a displacement sensor, with a mechano-electrical transducer associated with the stereocilia, the outer hair cell has a specialized basolateral membrane which produces a longitudinal force when the membrane potential changes. This force generator works at frequencies well into the acoustic range (Ashmore, 1987; Santos Sacchi, 1992; Dallos and Evans, 1995), and the available evidence suggests that it can produce sufficient force to determine the basilar membrane mechanics (Ruggero and Rich, 1991; Mammano and Ashmore, 1993).

\section{Frequency selectivity}

In the case of the mammalian cochlea, the frequency selectivity of the system (the ability to select sounds from a complex input signal) is intertwined with amplification. The effect of the outer hair cell force generator is to reduce the viscous damping of the fluid on the basilar membrane. As a result, each longitudinal section of the cochlea acts like a lightly damped resonator, so that the envelope of the traveling wave becomes both larger in amplitude as well as more localized. Thus, the frequency selectivity of the cochlea improves as a consequence of its amplification.

This particular design copes with the high-frequency demands of mammalian hearing. Other designs, adapted to a lower acoustic frequency range, have evolved in other vertebrates, where the hair cells can themselves act as selective electrical filters to a single frequency of stereocilial displacement. The properties of these cells have been well-documented, especially in frogs (Hudspeth and Lewis, 1988) and turtles (Art and Fettiplace, 1987). Because of the presence of voltage- and time-dependent $\mathrm{Ca}^{2+}$ and $\mathrm{K}^{+}$conductances in such hair cells, the membrane impedance behaves like an electrical resonator tuned to a specific frequency.

The electrically tuned hair cells of lower vertebrates cannot be used for signal detection at very high frequencies. Since electrical tuning depends on the interaction of ion channels in the cell basolateral membrane (Ashmore and Attwell, 1985; Art and Fettiplace, 1987), the appropriate time constant for ion channel gating limits the highest frequencies that can be extracted by this mechanism to $2 \mathrm{kHz}$, some $3-4$ octaves below the upper limit found in many mammals.

In mammals, where the tuning depends upon the macroscopic mechanics of the cochlea, the frequency limit is set in principle by the time constant of mechano-electrical transduction and the response of the force generator provided by the outer hair cells. Recent experiments indicate that the frequency response of this force generator extends to at least $20 \mathrm{kHz}$ (Dallos and Evans, 1995).

\section{Molecular mechanism of transduction in hair cells}

Transduction in hair cells is very fast. The kinetics of transduction have not been determined in detail, but the processes are likely to occur on a time scale of the order of microseconds (Corey and Hudspeth, 1979; Crawford et al., 1989), and this property ensures that hair cells can respond to acoustic stimuli. The upper limit of transuction kinetics is set by the time scale of protein conformation changes, and a gating time of $1 \mu \mathrm{sec}$ would set an upper bound of frequency detection at about 150 $\mathrm{kHz}$, a limit approached in some bat species. Hair cell transduction is not subject to the frequency limitations of photoreceptors and olfactory receptors because in hair cells the link between the mechanical displacement stimulus and the channel gating is simple and direct, without any intervening biochemical cascade.

The transducer channels in the hair cell membrane are located near the tips of the stereocilia (Jaramillo and Hudspeth, 1991). From evidence derived mainly from lower vertebrate species, these channels are cation-selective (Holton and Hudspeth, 1986; Crawford et al., 1989) and may well be the only ion channel type in the apical membrane (Roberts et al., 1990) although in mammalian species there appears to be purinergically gated ion channels present as well, (Housley et al., 1993). Electron microscopy reveals that the tips of the stereocilia are associated with only a few linkage protcins ("tip links") which coursc between adjacent stereocilia (Pickles et al., 1984). In the simplest model, the mechanosensitivity of the channels arises from deflection of the stereocilial bundle which changes the tension in the tip link and feeds energy directly into the transducer channel, thus leading to its opening (Pickles and Corey, 1992; Hudspeth and Markin, 1994). As a consequence the mechanosensory channels are opened and closed at the frequency of the stereocilial displacements.

Experiments on single hair cells allow measurement of the peak mechano-electrical transducer current $i$ elicited by a stereocilial displacement $x$ so that the dependence of $i(x)$ on $x$ can be determined (Corey and Hudspeth, 1983; Holton and Hudspeth, 1986; Crawford et al., 1989). This relationship has been found to be sigmoidal and can be described by an equation of the form 
$i(x) / i_{\max }=1 /\left\{\left[1+\exp \left(-a\left(x-x_{0}\right)\right)\right]\left[1+\exp \left(-b\left(x-x_{0}\right)\right)\right]\right\}$,

where $x_{0}, a$ and $b$ are constants. In turtle hair cells, $a=3 b=$ $10 \mathrm{\mu m}^{-1}$ when $x$ is measured in micrometers (Crawford et al., 1989). In the case of mammalian inner hair cells, the point where the stereocilia are at rest, the neutral set point $x_{0}$, corresponds to $i\left(x_{0}\right) / i_{\max } \approx 0.15$ although for outer hair cells, $i\left(x_{0}\right) / i_{\max } \approx 0.5$. In the latter case, the cell is operating near the position which corresponds to both maximum sensitivity and greatest linearity. This neutral position seems to be determined for outer hair cells by the mechanical bias arising from the surrounding structures of the organ of Corti (Dallos and Corey, 1991) whereas for the inner hair cells and other hair cell systems the neutral position is determined in part by intrinsic forces within the stereocilial bundle. There is now substantial evidence for a myosin-based motor, responsive to calcium entering the transducer channel (Assad and Corey, 1992; Solc et al., 1994), which retensions the tip link to ensure the operating point of the curve is appropriate.

Equation 4 is a nonlinear relation between $i(x)$ and bundle displacement, $x$, even for relatively small displacements near auditory threshold. This nonlincarity is believed to affect mechanical feedback of the outer hair cells and is likely to generate many of the nonlinear properties of the auditory system which include distortion products (Robles et al., 1991; Jaramillo et al., 1993) and otoacoustic-emissions, where sound is emitted from the cochlea.

In mammals, the auditory system responds to sounds from auditory threshold (corresponding to a sound wave with a pressure amplitude of $20 \mu \mathrm{Pa}$ ) up to $5 \log$ units above this level. Simultaneously, the system preserves its ability to discriminate frequencies which may differ by only $0.3 \%$. Hair cell sensitivity varies by about an order of magnitude between different species. In mammals the maximum sensitivity of the hair cell is about 1 $\mathrm{mV} / \mathrm{nm}$ displacement of the stereocilia (or approximately $10 \mathrm{pA}$ / $\mathrm{nm}$, in terms of current). This figure is determined by the maximal conductance of the transducer (about $5 \mathrm{nS}$ ) and the input electrical properties of the basolateral cell membrane (Kros et al., 1992). The high sensitivity means that large signals can saturate the receptor's response, as in the other sensory systems, and the wide range of sensory coding employs gain-controlling mechanisms at the hair cell itself as well as acting to limit the sound input delivered accessory structures surrounding the cells.

In lower vertebrates there is a pronounced adaptation of the transducer current when the stereocilial bundle is displaced by a fixed distance (Eatock et al., 1987; Crawford et al., 1989), as shown in Figures $2 C$ and $3 F$. This is equivalent to alteration of $a$ and $b$ in the $i(x)$ curve (Eq. 4 ). Where the response to a sustained displacement has been measured (e.g., in frog and turtle hair cells) the effect is a resetting of the neutral set point without any significant reduction of the dynamic range. The mechanism proposed to mediate this effect is again an entry of calcium through mechanosensory channels which retensions the linkage to the ion channels (Assad and Corey, 1992; Hudspeth and Gillespie, 1994). Although such adaptation effects are prominent in hair cells of lower vertebrates, adaptation in mammalian hair cells, which can be observed in the transducer currents shown in Figure $2 C$, is less pronounced. In mammals the synapse between the inner hair cell and the afferent fiber is likely to be responsible for the observed reduction of firing rate in the auditory nerve when prolonged tone stimuli are delivered to the ear.

\section{Noise in hair cells}

The existence of substantial electrical noise in hair cells means that recordings usually have to be averaged from multiple repetitions of the stimulus in order that the response can be determined. The sources of noise can be divided into those which arise from (a) the thermal fluctuations associated with the Brownian motion of the stereocilial bundle, (b) spontaneous fluctuations in the opening of the transduction channels at the apical pole of the cell, and (c) spontaneous fluctuations in the opening and closing of ion channels in the basolateral membrane of the receptor. There is relatively little quantitative information about the relative contribution of each source. Of these, mechanism (a) appears to dominate in cells with free-standing stereocilia, causing wideband fluctuations comparable in amplitude with the signal at auditory threshold. Source (b) is measurable (Holton and Hudspeth, 1986). Indeed, the single channel conductance can be estimated in this way and is found to be about $100 \mathrm{pS}$ (Crawford et al., 1991). The weighting given to noise source $(\mathrm{h})$ relative to noise source (c) will depend on the precise type of hair cell under consideration. Since the membrane time constant of hair cells typically lies between 0.1 and $1 \mathrm{msec}$, the voltage noise arising from all sources of fluctuation in the cell will be filtered above $2 \mathrm{kHz}$.

The estimate of the signal-to-noise ratio for cochlear transduction, present at the inner hair cell synapse, depends on detailed assumptions about cochlear mechanics. In particular, it depends on the number of mechanical degrees of freedom (for example, the numbers of hair bundles) involved in cochlear processing. For a given input frequency, and assuming purely passive cochlear mechanics, the signal-to-noise ratio at the inner hair cells has been calculated to lie between 0.02 (in the case where the cell bundles are individually subject to thermal stimulation) and 11 (in the case where the bundles in different cells are coupled together, thus reducing the number of independent degrees of mechanical freedom; Harris, 1967). This calculation has not been carried out for a cochlea with active mechanical amplification.

Thus, in the auditory system, the accessory structures need to be designed to minimize the effects of the intrinsic thermal noise which may exceed the input signal. Some mechanical coupling between the cells in the cochlea needs to be present to ensure that the acoustic signal is not drowned in thermal noise. But, as with electrical coupling between photoreceptors, which leads to a compromised spatial resolution, lowered noise in the cochlea is obtained at the expense of reduced frequency resolution.

\section{Signal Processing Aspects of Sensory Transduction}

Artificial as well as natural sensors are designed to detect specific kinds of stimuli (such as sound or light) and are specialized for the detection of particular sensory modalities. To appreciate how, in the case of both artificial and natural sensors, an optimization of performance has been achieved, it is useful to analyze sensory transduction in terms of signal-processing and the signal-to-noise ratio.

\section{Bandwidth, gain, and signal-to-noise ratio}

The electrical transduction of input signals to photoreceptors and olfactory receptors is relatively slow, as a result of the trade-off between temporal response and amplification in the G-protein cascade. Thus, in order for these receptor cells to achieve very high gain, it is necessary for them to reduce bandwidth. In ad- 
dition to allowing a higher gain, the lower bandwidth has the advantage of increasing the signal-to-noise ratio within the transduction process. Associated with the slow time-course of their responses, photoreceptors and olfactory receptor cells have relatively long membrane time constants (about 10-50 msec in the rods and cones of lower vertebrates; Bader et al., 1979; Perry and McNaughton, 1991). In this way it is possible to filter out noise arising from fast channel fluctuations, as well as wide noise from the G-protein cascade. In dark-adapted monkey rods, the dominant component of noise (the "continuous" component) has a standard deviation of about $0.17 \mathrm{pA}$ over the bandwidth of the flash response, while the amplitude of the single-photon response is about $0.7 \mathrm{pA}$ (Baylor et al., 1984). The ratio of these two parameters can be used to estimate the signal-to-noise ratio of a maximally sensitive monkey rod as about 4 . Because of this large signal-to-noise ratio, the single-photon event is reliably detectable at the level of the dark-adapted monkey rod photoreceptor. In the presence of steady illumination, however, detection by the light-adapted rod of a light flash has to be performed in the presence of a random stream of photon events arising from the background light. Detection of a very weak signal under these circumstances is inevitably occurring at a more central stage, with (for example) a retinal ganglion cell collecting and correlating signals from a large number of photoreceptors.

One mechanism which has evolved in the retina to cope with photoreceptor noise is electrical coupling between photoreceptors of the same kind. For stimuli of wide spatial extent, this electrical coupling reduces the absolute noise level without af fecting the sensitivity, and therefore increases the signal-to-noise ratio (Lamb and Simon, 1976).

Auditory hair cells are specialized for responding to signals with a much greater frequency range $(40-20,000 \mathrm{~Hz})$ than the G-protein-coupled rods and cones $(0-50 \mathrm{~Hz})$. In these cells the membrane time constant is of necessity much shorter (as low as $0.1 \mathrm{msec}$ ), and it is not therefore possible to filter out highfrequency fluctuations without losing the signal of interest.

\section{Energy gain}

Sensory transduction is not a passive process, but requires the release of free energy which has been stored in an electrochemical gradient or in chemical bonds. A rod photoreceptor, upon absorption of single photon, produces an electrical signal of about $1 \mathrm{pA}$ with an integration time of $0.7 \mathrm{sec}$ in cold-blooded animals, or of $0.2 \mathrm{sec}$ in mammals. For a driving voltage of about $-40 \mathrm{mV}$, these charge movements correspond to an expenditure of free energy of about $10^{-14} \mathrm{Joule} /$ photon, indicating that during phototransduction the rod utilizes the free energy of a photon (about 10-19 Joule/photon; see "The sensory world: quantum versus classical") to modulate an energy change about 5 orders of magnitude larger. The olfactory receptor cell appears to respond to the binding of an odorant molecule with a current signal of about $0.5 \mathrm{pA}$, with a driving voltage and integration time similar to that of a rod photoreceptor. Therefore, assuming binding energies of $10^{-19}$ or $10^{-20} \mathrm{Joule} /$ photon (see "The sensory world: quantum versus classical" and Block, 1992), the energy gain associated with chemotransduction is similarly at least 5 orders of magnitude. A comparable calculation for hair cells is more difficult to make, but it is nevertheless clear that in this case too transduction is associated with a large energy gain.

\section{Summary}

In photoreceptors, olfactory receptor cells and auditory receptor cells, transduction has cvolved to optimize performance in terms of sensitivity, signal-to-noise ratio and the ability to extend the dynamic range. In photoreceptors and olfactory receptor cells, the molecular mechanisms underlying transduction involve closely similar enzymatic cascades, whereas in auditory receptor cells transduction proceeds by direct gating of mechanosensory channels, to achieve rapid transduction. The ion channels in the sensory membrane of these three types of receptor cells are all cation selective; they do not discriminate sharply between different alkali cations and are permeable to divalent ions. The entry of $\mathrm{Ca}^{2+}$ through these channels is an essential feature of transduction in all three sensory receptors, and appears to be involved in regulating the adaptational state of transduction. Each of the three sensory receptors consumes metabolic energy at a significant rate, and signal transduction involves the modulation of this energy consumption.

Nature's solution to the problem of translating various aspects of the physical world into electrical signals that are amenable to further processing by the nervous system has led to proteinbased processes that exhibit much more sophistication than the transducing systems encountered in man-made photomultipliers and microphones. Biological transducers are much more than devices in which physical processes lead to the extraction of photoelectrons or the creation of electron/hole pairs. In addition, they are subject to the demanding constraint of taking care of their own integrity and neural connectivity throughout the life of their host. They deserve to be called "smart sensors."

\section{References}

Art JJ, Fettiplace R (1987) Variation of membrane properties in hair cells isolated from the turtle cochlea. J Physiol (Lond) 358:323-348.

Ashmore JF (1987) A fast motile response in guinea-pig outer hair cells: the cellular basis of the cochlear amplifier. J Physiol (Lond) 388:323-348.

Ashmore JF (1994) The G.L. Brown Prize Lecture: the cellular machinery of the cochlea. Exp Physiol 79:113-134.

Ashmore JF, Attwell D (1985) Models for electrical tuning in hair cells. Proc R Soc Lond [Biol] 226:325-344.

Ashmore JF, Kolston PJ (1994) Hair cell based amplification in the cochlea. Curr Opinion Neurobiol 4:503-508.

Assad JA, Corey DP (1992) An active motor model for adaptation by vertebrate hair cells. J Neurosci 12:3291-3309.

Bader CR, MacLeish PR, Schwartz EA (1979) A voltage-clamp study of the light response in solitary rods of the tiger salamander. J Physiol (Lond) 296:1-26.

Baylor DA, Hodgkin AL (1974) Changes in time scale and sensitivity in turtle photoreceptors. J Physiol (Lond) 242:729-758.

Baylor DA, Hodgkin AL, Lamb TD (1974) The electrical response of turtle cones to flashes and steps of light. J Physiol (Lond) 242:685727.

Baylor DA, Lamb TD, Yau K-W (1979) Responses of retinal rods to single photons. J Physiol (Lond) 288:613-634.

Baylor DA, Matthews G, Yau K-W (1980) Two components of electrical dark noise in toad retinal rod outer segments. J Physiol (Lond) 309:591-621.

Baylor DA, Nunn BJ, Schnapf JL (1984) The photocurrent, noise and spectral sensitivity of rods of the monkey Macaca fascicularis. J Physiol (Lond) 357:575-607.

Block SM (1992) Biophysical principles of sensory transduction. In: Sensory transduction (Corey DP, Roper SD, eds), pp 1-17. New York: Rockefeller UP.

Buck L, Axel R (1991) A novel multigene family may encode odorant receptors: a molecular basis for odor recognition. Cell 65:175-187.

Burkhardt DA (1994) Light adaptation and photopigment bleaching in cone photoreceptors in situ in the retina of the turtle. J Neurosci 14: $1091-1105$. 
Corey DP, Hudspeth AJ (1979) Response latency of vertebrate hair cells. Biophys J 26:499-506.

Corey DP, Hudspeth AJ (1983) Kinetics of the receptor current in bullfrog saccular hair cells. J Neurosci 3:962-976.

Crawford AC, Evans MG, Fettiplace R (1989) Activation and adaptation on transducer currents in turtle hair cells. J Physiol (Lond) 419: 405-134.

Crawford AC, Evans MG, Fettiplace R (1991) The action of calcium on the mechano-electric transducer current of turtle hair cells. J Physiol (Lond) 434:369-398.

Dallos P (1992) The active cochlea. J Neurosci 12:4575-4585.

Dallos P, Corey ME (1991) The role of the outer hair cell motility in cochlear tuning. Curr Opinion Neurobiol 1:215-220.

Dallos P, Evans BN (1995) High-frequency motion of outer hair cells and the cochlear amplifier. Science 267:2006-2009.

Eatock RA, Corey DP, Hudspeth AJ (1987) Adaptation of mechanoelectrical transduction in hair cells of the bullfrog's sacculus. J Neurosci 7:2821-2836.

Fain GL, Matthews HR (1990) Calcium and the mechanism of light adaptation in vertebrate photoreceptors. Trends Neurosci 13:378-384.

Firestein S, Werblin $F$ (1989) Odor-induced membrane currents in vertebrate-olfactory receptor neurons. Science 244:79-82.

Firestein S, Shepherd GM, Werblin FS (1990) Time course of the membrane current underlying sensory transduction in salamander olfactory receptor neurones. J Physiol (Lond) 430:135-158.

Firestein S, Picco C, Spadavecchia L, Menini A (1993) The relation between stimulus and response in olfactory receptor cells of the tiger salamander. J Physiol (Lond) 468:1-10.

Forti S, Menini A, Rispoli G, Torre V (1989) Kinetics of phototransduction in retinal rods of the newt Triturus cristatus. J Physiol (Lond) 419:265-295.

Gorczyca WA, Gray-Keller MP, Detwiler PB, Palczewski K (1994) Purification and physiological identification of a guanylate cyclase activating protein from retinal rods. Proc Natl Acad Sci USA 91:40144018

Gray-Keller MP, Detwiler PB (1994) The calcium feedback signal in the phototransduction cascade of vertebrate rods. Neuron 13:849861.

Hamill OP, McBride DW (1994) The cloning of a mechano-gated membrane ion channel. Trends Neurosci 17:439-443.

Harris GG (1967) Brownian motion in the cochlear partition. J Acoust Soc Am 44:176-186.

Hecht S, Shlaer S, Pirenne MH (1942) Energy, quanta, and vision. J Gen Physiol 25:819-840.

Hestrin S, Korenbrot JI (1990) Activation kinetics of retinal cones and rods: response to intense flashes of light. J Neurosci 10:1967-1973.

Holton T, Hudspeth AJ (1986) The transduction channel of hair cells from the bullfrog characterized by noise analysis. J Physiol (Lond) 375:195-227.

Housley GD, Greenwood RA, Ashmore JF (1993) Localization of cholinergic and purinergic receptors on outer hair cells isolated from the guinea pig cochlea. Proc R Soc Lond [Biol] 249:265-273.

Hsu Y-T, Molday RS (1993) Modulation of the cGMP-gated channel of rod photoreceptor cells by calmodulin. Nature 361:76-79.

Hudspeth AJ, Gillespie PG (1994) Pulling strings to tune transduction: adaptation by hair cells. Neuron 12:1-9.

Hudspeth $\Lambda J$, Lewis RS (1988) Kinetic analysis of voltage and iondependent conductances in saccular hair cells of the bull-frog, Rana catesbiana. J Physiol (Lond) 400:237-274.

Hudspeth AJ, Markin VS (1994) The ear's gears. Physics Today 47: $22-28$.

Jaramillo F, Hudspeth AJ (1991) Localization of the hair cell's transduction channels at the hair bundle's top by iontophoretic application of a channel blocker. Neuron 7:409-420.

Jaramillo F, Markin VS, Hudspeth AJ (1993) Auditory illusions and the single hair cell. Nature 364:527-529.

Karpen, Loney, Baylor (1992) Cyclic GMP-activated channels of salamander retinal rods: spatial-distribution and variation of responsiveness. J Physiol (Lond) 448:257-274.

Kaupp UB (1991) The cyclic nucleotide-gated channels of vertebrate photoreceptors and olfactory epithelium. Trends Neurosci 14:150157.

Kaupp UB, Koch K-W (1992) Role of cGMP and $\mathrm{Ca}^{2+}$ in vertebrate photoreceptor excitation and adaptation. Annu Rev Physiol (Lond) $54: 153-175$.
Kawamura S (1993a) Rhodopsin phosphorylation as a mechanism of cyclic GMP phosphodiesterase regulation by S-modulin. Nature 362 : $855-857$.

Kawamura S (1993b) Molecular aspects of photoreceptor adaptation in vertebrate retina. Int Rev Neurobiol 35:43-86.

Kawamura S, Murakami M (1991) Calcium-dependent regulation of cyclic GMP phosphodiesterase by a protein from frog retinal rods. Nature 349:420-423.

Kleene SJ, Gesteland RC (1991) Calcium-activated chloride conductance in frog olfactory cilia. $J$ Neurosci 11:3624-3629.

Koch K-W (1991) Purification and identification of photoreceptor guanylate cyclase. J Biol Chem 266:8634-8637.

Koch K-W, Stryer L (1988) Highly cooperative feedback control of retinal rod guanylate cyclase by calcium ions. Nature 334:64-66.

Kros CJ, Rüsch A, Richardson GP (1992) Mechano-electric transduction currents in hair cells of the neonatal mouse cochlea. Proc R Soc Lond [Biol] 656:1-11.

Kurahashi T (1989) Activation by odorants of cation-selective conductance in the olfactory receptor cell isolated from the newt. J Physiol (Lond) 419:177-192.

Kurahashi T, Kaneko A (1991) High density cAMP-gated channels at the ciliary membrane in the olfactory receptor cell. Neuroreport 2:5-8.

Kurahashi T, Shibuya T (1990) Ca-dependent adaptive properties in the solitary olfactory receptor cell of the newt. Brain Res 515:261268

Kurahashi T, Yau K-W (1993) Co-existence of cationic and chloride components in odorant-induced current of vertebrate olfactory receptor cells. Nature 363:71-74.

Lagnado L, Baylor DA (1994) Calcium controls light-triggered formation of catalytically active rhodopsin. Nature 367:273-277.

Lagnado L, Cervetto L, McNaughton PA (1992) Calcium homeostasis in the outer segments of retinal rods from the tiger salamander. $J$ Physiol (Lond) 455:111-142.

Lamb TD (1980) Spontaneous quantal events induced in toad rods by pigment bleaching. Nature 287:349-351.

Lamb TD (1981) The involvement of rod photoreceptors in dark adaptation. Vision Res 21:1773-1782.

Lamb TD, McNaughton PA, Yau K-W (1981) Spatial spread of activation and background desensitization in rod outer segments. J Physiol (Lond) 319:463-496.

Lamb TD, Pugh EN Jr (1992) A quantitative account of the activation steps involved in phototransduction in amphibian photoreceptors. $\mathbf{J}$ Physiol (Lond) 449:719-757.

Lamb TD, Simon EJ (1976) The relation between intercellular coupling and electrical noise in turtle photoreceptors. J Physiol (Lond) 263: 257-286.

Lamb TD, Simon EJ (1977) Analysis of electrical noise in turtle cones. J Physiol (Lond) 272:435-468.

Leibrock CS, Reuter T, Lamb TD (1994) Dark adaptation of toad rod photoreceptors following small bleaches. Vision Res 34:2787-2800.

Mammano F, Ashmore (1993) Reverse transduction measured in the isolated cochlea by laser Michelson interferometry. Nature 365:838841.

Matthews HR (1991) Incorporation of calcium chelator into guineapig rods shows that calcium mediates mammalian photoreceptor light adaptation. J Physiol (Lond) 436:93-105.

Matthews HR, Murphy RLW, Fain GL, Lamb TD (1988) Photoreceptor light adaptation is mediated by cytoplasmic calcium concentration. Nature 334:67-69.

McCarthy ST, Younger JP, Owen W (1994) Free calcium concentrations of bullfrog rods determined in the presence of multiple forms of fura-2. Biophys J 67:2076-2089.

McNaughton PA (1991) Light response of vertebrate photoreceptors. Physiol Rev 70:847-883.

Menini A (1995) Cyclic nucleotide-gated channels in visual and olfactory transduction. Biophys Chem, in press.

Menini A, Picco C, Firestein S (1995) Quantal-like current fluctuations induced by odorants in olfactory receptor cells. Nature 373:435-437.

Nakamura T, Gold GH (1987) A cyclic nucleotide-gated conductance in olfactory receptor cilia. Nature 325:442-444.

Nakatani K, Yau K-W (1988) Calcium and light adaptation in retinal rods and cones. Nature 334:69-71.

Perry M, McNaughton PA (1991) Response properties of cones from the retina of the tiger salamander. J Physiol (Lond) 433:561-587. 
Pickles JO, Corcy DP (1992) Mechanoelectric transduction by hair cells. Trends Neurosci 15:254-259.

Pickles JO, Osborne M, Comis SD (1984) Crosslinks between the stereocilia in the guinea pig organ of Corti, and the possible relation to sensory transduction. Hearing Res 15:103-112.

Pugh EN Jr, Lamb TD (1993) Amplification and kinetics of the activation steps in phototransduction. Biochim Bionhys Acta 1141:111149.

Ratto GM, Payne R, Owen WG, Tsien RY (1988) The concentration of cytosolic free $\mathrm{Ca}^{2+}$ in vertebrate rod outer segments measured with fura-2. J Neurosci 8:3240-3246.

Reed RR (1992) Signaling pathways in odorant detection. Neuron $8: 205-209$.

Ressler KJ, Sullivan SL, Buck LB (1994) A molecular dissection of spatial patterning in the olfactory system. Current Opinion Neurobiol 4:588-596.

Roberts WM, Jacobs RA, Hudspeth AJ (1990) Colocalization of ion channels involved in frequency selectivity and synaptic transmission at presynaptic active zones of hair cells. J Neurosci 10:3664-3684.

Robles L, Ruggero MA, Rich NC (1991) Two-tone distortion in the basilar membrane of the cochlea. Nature 349:413-414.

Ross EM (1989) Signal sorting and amplification through G-protein coupled receptors. Neuron 3:141-152.

Ruggero M, Rich NC (1991) Furosemide alters organ of Corti mechanics: evidence for feedback of outer hair cell upon the basilar membrane. J Neurosci 11:1057-1067.

Rüsch A, Kros CJ, Richardson GP (1994) Block by amiloride and its derivatives of mechano-electrical transduction in outer hair cells of mouse cochlear cultures. J Physiol (Lond) 474:75-86.

Santos Sacchi J (1992) On the frequency limit and phase of outer hair cell motility: the effects of the membrane filter. J Neurosci 12:19061915.

Sellick PM, Patuzzi R, Johnstone BM (1982) Measurement of basilar membrane motion in the guinea pig using the Mossbauer technique. J Acoust Soc Am 72:131-141.

Sesti F, Straforini M, Lamb TD, Torre V (1994) Gating, selectivity and blockage of single channels activated by cyclic GMP in retinal rods of the tiger salamander. J Physiol (Lond) 474:203-222.

Shepherd GM (1994) Discrimination of molecular signals by the olfactory receptor neuron. Neuron 13:771-790.

Solc CK, Derfler BH, Duyk GM, Corey DP (1994) Molecular cloning of myosins from the bullfrog saccular macula: a candidate for the hair cell adaptation motor. Audit Neurosci 1:63-75.

Stryer L (1991) Visual excitation and recovery. J of Biol Chem 266: 10711-10714.

Taylor WR, Baylor DA (1995) Conductance and kinetics of single cGMP-activated channels in salamander rod outer segments. J Physiol (Lond) 483:567-582.

Torre V, Menini A (1994) Selectivity and single-channel properties of the cGMP-activated channel in amphibian retinal rods. In: Handbook of membrane channels (Peracchia C, ed), pp 345-357. Ncw York: Academic.

Torre V, Matthews HR, Lamb TD (1986) Role of calcium in regulating the cyclic nucleotide cascade of phototransduction in retinal rods. Proc Natl Acad Sci USA 83:7109-7113.

Torre V, Straforini M, Sesti F, Lamb TD (1992) Different channelgating properties of two classes of cGMP-activated channel in vertebrate photoreceptors. Proc R Soc Lond [Biol] 250:209-215.

von Bekesy G (1960) Experiments in hearing. New York: McGraw Hill.

Yau K-W, Baylor DA (1989) Cyclic GMP-activated conductance of retinal photoreceptor cells. Annu Rev Neurosci 12:289-327.

Yau K-W, Nakatani K (1985) Light-induced reduction of cytoplasmic free calcium in retinal rod outer segment. Nature 313:579-582.

Zufall F, Firestein S, Shepherd GM (1994) Cyclic nucleotide-gated ion channels and sensory transduction in olfactory receptor neurons. Annu Rev Biophys Biomol Struct 23:577-607. 